\title{
Should be or Not Use Haematopoietic Growth Factors in the Case of Drug- induced Agranulocytosis
}

\author{
Emmanuel Andrès*, Rachel Mourot, Olivier Keller and Adrian Purcarea \\ Department of Internal Medicine, B Clinic, University Hospital of Strasbourg, Strasbourg, 67000 Strasbourg, France
}

Keywords: Agranulocytosis; Neutropenia; Haematopoietic growth factors; G-CSF

Drug-induced agranulocytosis is characterized by a severe decrease of neutrophil count of at least $<0.5 \times 109 / \mathrm{L}$, in association with the intake of drugs such as: anti-thyroid drugs, antibiotics, ticlopidine, sulfasalazine, and dipyrone [1]. Currently, the incidence of this idiosyncratic adverse effect is estimated to be between 2.4 and 15.4 cases per one million inhabitants. From a clinical perspective, druginduced agranulocytosis may simply be detected following a routine full blood count, or it may present with the onset of infection with varying degrees of severity, for example, ranging from fever with no clear focus, septicaemia and septic shock, to more localized infections mostly involving the ear nose and throat, the lungs and the skin $[1,2]$.

In oldest studies, the mortality of drug-induced agranulocytosis due to complications resulting from infection ranged from $10 \%$ to $16 \%$ [2]. At present, this mortality is closer to $5 \%$ (between $2.5 \%$ and $10 \%$ ), illustrating the progress that has been made in the recognition and therapeutic management of this condition [1]. Notify that drug-induced agranulocytosis can rapidly become a life threatening condition, hence the importance of optimal clinical management. To our opinion, this includes the use of haematopoietic growth factors such as Granulocyte Colony-Stimulating Factor (G-CSF), which are not yet, in developed countries, licenced for this condition [3].

To date, the efficacy and mainly the usefulness of haematopoietic growth factors in drug-induced agranulocytosis is still a matter of debate. A systematic meta-analysis by Andersohn et al. $(n=492)$ found that since 1985 over two-thirds of reported cases were treated with these agents [2]. Most recent studies demonstrate a significant reduction in the duration of agranulocytosis following the use of these cytokines $[2,3]$. In our own experience, the administration of G-CSF, at a mean dose of $300 \mu \mathrm{g} / \mathrm{day}$, is associated with a significant reduction in the duration of agranulocytosis, antibiotic use and length of hospital stay, particularly in patients with poor prognostic factors [4,5]. Only one single study showed a survival benefit when using neutrophil growth factors [6]. The most recent data did not find any significant difference in the mortality rate of patients treated or not treated with G-CSF or GM-CSF: $5 \%$ versus $6 \%$ in the study of Andersohn et al.; $8.9 \%$ versus $11.4 \%$ in the study of Ibanez et al. [2,7]. The prospective, randomized study carried out by Fukata et al. (the only one available to date), was also unable to draw any definitive conclusions regarding the use of neutrophil growth factors [8].

A critical review of the data available support the role of neutrophil growth factors in the presence of at least one of the poor prognostic factors $[1,9,10]$. In our experience, these factors includes: age over 65 years, neutrophil count at diagnosis of less than $0.1 \times 10^{9} / \mathrm{L}$, development of severe intercurrent infection (septicaemia and septic shock) as well as pre-existing co-morbidities (in particular renal impairment, defined by a serum creatinine level $>120 \mu \mathrm{mol} / \mathrm{L}$ ) [10]. A neutrophil count of $<0.1 \times 10^{9} / \mathrm{L}$ appears to be a particularly important prognostic factor $[9,10]$.

To date, the true impact of the use of haematopoietic growth factors is still being questioned, but these molecules appear to indisputably decrease the duration of agranulocytosis, antibiotic course and length of hospital stay. Finally, it would be beneficial to conduct further public health studies (such as meta-analysis of reported data form the series of Berlin, Barcelona, Strasbourg...) in order to fully confirm the potential use of these agents.

\section{Conflict of Interest}

The authors have no conflicts of interest that are directly relevant of the content of this manuscript. Professor E. Andrès is recipient of a grant from the Laboratoires AMGEN, NOVARTIS, AVANTIS, GSK, PFIZER, FERRING and CHUGAI, but this sponsor had no part in the research or writing of the present manuscript. Professor E. Andrès is an active member of the various French national or international commissions or group, but the present manuscript represents individual opinion.

\section{References}

1. Andrès $E$, Maloisel $F$ (2008) Idiosyncratic drug-induced agranulocytosis or acute neutropenia. Curr Opin Hematol 15: 15-21.

2. Andersohn F, Konzen C, Garbe E (2007) Systematic review: agranulocytosis induced by nonchemotherapy drugs. Ann Intern Med 146: 657-665.

3. Andrès E, Maloisel F, Zimmer J (2010) The role of haematopoietic growth factors granulocyte colony-stimulating factor and granulocyte-macrophage colony-stimulating factor in the management of drug-induced agranulocytosis. Br J Haematol 150: 3-8.

4. Andrès E, Kurtz JE, Perrin AE, Dufour P, Schlienger JL, et al. (2001) Haematopoietic growth factor in antithyroid-drug-induced agranulocytosis. QJM 94: 423-428.

5. Andrès E, Kurtz JE, Martin-Hunyadi C, Kaltenbach G, Alt M, et al. (2002) Nonchemotherapy drug-induced agranulocytosis in elderly patients: the effects of granulocyte colony-stimulating factor. Am J Med 112: 460-464.

6. Beauchesne MF, Shalansky SJ (1999) Nonchemotherapy drug-induced agranulocytosis: a review of 118 patients treated with colony-stimulating factors. Pharmacotherapy 19: 299-305.

7. Ibáñez L, Sabaté M, Ballarín E, Puig R, Vidal X, et al. (2008) Agranulocytosis and Aplastic Anaemia Study Group of Barcelona. Use of granulocyte colonystimulating factor (G-CSF) and outcome in patients with non-chemotherapy agranulocytosis. Pharmacoepidemiol Drug Safety 17: 224-228.

8. Fukata S, Kuma K, Sugawara M (1999) Granulocyte colony-stimulating factor (G-CSF) does not improve recovery from antithyroid drug-induced agranulocytosis: a prospective study. Thyroid 9: 29-31.

*Corresponding author: Pr. E. Andres, Service de Médecine Interne, Clinique Médicale B, CHRU de Strasbourg, 1 Place de l'Hôpital, 67000 Strasbourg Cedex, France, Tel: +33 (3) 881150 66; Fax: +33 (3) 881162 62; E-mail: emmanuel.andres@chru-strasbourg.fr

Received January 14, 2014; Accepted January 23, 2014; Published January 26, 2014

Citation: Andrès E, Mourot R, Keller O, Purcarea A (2014) Should be or Not Use Haematopoietic Growth Factors in the Case of Drug-induced Agranulocytosis. J Blood Disorders Transf 5: e108. doi: 10.4172/2155-9864.1000e108

Copyright: $\odot 2014$ Andrès $E$, et al. This is an open-access article distributed unde the terms of the Creative Commons Attribution License, which permits unrestricted use, distribution, and reproduction in any medium, provided the original author and source are credited. 
Citation: Andrès E, Mourot R, Keller O, Purcarea A (2014) Should be or Not Use Haematopoietic Growth Factors in the Case of Drug-induced Agranulocytosis. J Blood Disorders Transf 5: e108. doi: 10.4172/2155-9864.1000e108

Page 2 of 2

9. Juliá A, Olona M, Bueno J, Revilla E, Rosselló J, et al. (1991) Drug-induced agranulocytosis: prognostic factors in a series of 168 episodes. $\mathrm{Br} \mathrm{J}$ Haematol 79: 366-371
10. Maloisel F, Andrès E, Kaltenbach G, Noel E, Koumarianou A (2003) Prognostic factors of hematologic recovery in nonchemotherapy drug-induced agranulocytosis. Haematologica 88: 470-471.

Citation: Andrès E, Mourot R, Keller O, Purcarea A (2014) Should be or Not Use

Haematopoietic Growth Factors in the Case of Drug-induced Agranulocytosis. J Blood Disorders Transf 5: e108. doi: 10.4172/2155-9864.1000e108 